\section{IDDF2018-ABS-0052 FACTORS AFFECTING LOCATION OF COLONIC DIVERTICULITIS IN FILIPINOS ADMITTED AT MAKATI MEDICAL CENTRE}

Ana Monica Estrella*, Patricia Cabral - Prodigalidad. Makati Medical Center, Philippines

\subsection{6/gutjnl-2018-IDDFabstracts.87}

Background There is an increasing trend of right-sided acute colonic diverticulitis seen in the young Asian population.

Methods A retrospective cross-sectional study of 169 Filipino patients diagnosed with colonic diverticulitis in Makati Medical Centre, a tertiary care facility, from June 2012 to June 2016 to determine the risk factors associated with the location of disease.

Results Among the subjects, 46\% (77/169) had right-sided diverticulitis and 54\% (92/169) had left-sided diverticulitis. Young age of 18-50 years old (OR 2.92, CI 1.33-6.44), and normal BMI or body mass index (OR 2.43; CI 1.00-5.50) are independent predictors of right-sided diverticulitis. Furthermore, older age (above 50 years old) (OR 2.986; CI 0.1530.73 ) and obese II (OR 5.565; CI 1.679-18.445) are associated with left-sided diverticulitis (table 1 and table 2).

Abstract IDDF2018-ABS-0052 Table 1 Profile of patients diagnosed with colonic diverticulitis $(\mathrm{N}=169)$

\begin{tabular}{lccc}
\hline Characteristics & $\begin{array}{c}\text { Left Sided } \\
\mathbf{n}=92\end{array}$ & $\begin{array}{c}\text { Right Sided } \\
\mathbf{n}=77\end{array}$ & p-value \\
\hline Age groups & & & \\
$\begin{array}{l}18-50 \text { years old } \\
\text { Above } 50 \text { years old }\end{array}$ & $36[39.1 \%]$ & $54[70.1 \%]$ & $<0.001$ \\
Sex & $56[60.9 \%]$ & $23[29.9 \%]$ & $<0.001$ \\
Male & $57[62 \%]$ & $42[54.5 \%]$ & 0.207 \\
Female & $35[38 \%]$ & $35[45.5 \%]$ & 0.207 \\
BMI (Asia Pacific) & & & \\
Normal (18.5-22.9) & $13[14.1 \%]$ & $25[32.5 \%]$ & 0.004 \\
Underweight (<18.5) & $3[3.3 \%]$ & $2[2.6 \%]$ & 0.584 \\
Overweight (23- & $20[21.7 \%]$ & $18[23.4 \%]$ & 0.471 \\
24.9) & & & \\
Obese I(23-24.9) & $33[35.9 \%]$ & $27[35.1 \%]$ & 0.521 \\
Obese II (>29.9) & $23[25 \%]$ & $4[5.2 \%]$ & $<0.001$ \\
\hline
\end{tabular}

Abstract IDDF2018-ABS-0052 Table 2 Independent risk factors for right sided and left sided diverticulitis

\begin{tabular}{lcc}
\hline Variables in the Equation & OR $(95 \% \mathrm{Cl})$ & p value \\
\hline Right Sided Diverticulitis & & \\
Age, $18-50$ years old & $2.92(1.33-6.44)$ & 0.008 \\
Normal BMI & $2.34(1.00-5.50)$ & 0.050 \\
Left Sided Diverticulitis & $2.986(1.37-6.508)$ & \\
Age, $>50$ years old & $5.565(1.679-18.445)$ & 0.006 \\
Obese II BMI & & 0.005 \\
\hline
\end{tabular}

Conclusions In the Filipino population employed in the study, young age and normal BMI are associated with increased risk for right-sided diverticulitis while older age and obesity are correlated with left-sided diverticulitis.

\section{IDDF2018-ABS-0053 CLINICAL SIGNIFICANCE OF SEPRASE IN GASTRIC CANCER AND ITS PROGNOSTIC VALUE ON APATINIB}

${ }^{1}$ Yunqi Hua*, ${ }^{2}$ Fangrui Yin, ${ }^{1}$ Yongyan Yang, ${ }^{1}$ Xianfeng Liu, ${ }^{1}$ Cuiyun Zhao, ${ }^{1}$ Yunjian Jin, ${ }^{1}$ Wenhui Zhang, ${ }^{1} \mathrm{Min}$ Li, ${ }^{1}$ Meili Zhao, ${ }^{1} \mathrm{Na}$ Jin. ${ }^{1}$ Cancer Biotherapy Center and Oncology Department, Baotou Tumor Hospital, Clinical Oncology of Baotou Medical College, China; ${ }^{2}$ Department of Central Laboratory, The First Affiliated Hospital of Baotou Medical College, Baotou, Inner Mongolia, China

\subsection{6/gutjnl-2018-IDDFabstracts.88}

Background Apatinib, a novel inhibitor of VEGFR-2, has achieved survival improvement in advanced gastric cancer patients as the third-line treatment medicine. But lacking effective prognostic indicators, we investigated the expression of Seprase protein in gastric cancer and its prognostic value on apatinib.

Methods We conducted a retrospective study using data on 45 apatinib-treated advanced gastric cancer (GC), and 15 cases of normal gastric tissue $>5 \mathrm{~cm}$ from the tumour was selected as control group. The immunohistochemical method was used to detect the expression of Seprase in two group, the relationship between Seprase expression and the clinicopathologic characteristics was studied. 45 GC patients were divided into two groups: seprase-negative and seprase-positive group. All the patients were orally given apatinib at a dose of $500 \mathrm{mg} / \mathrm{day}$, and its prognostic significance and clinical efficacy on apatinib were statistically analysed.

Results The positive rate of seprase in GC was 71.11\% (32/ $45)$ higher than that in normal tissue $20.00 \%$ (3/15) and with statistical significance $\left(\chi^{2}=6.67, \mathrm{p}=0.01\right)$; Seprase was related to the degree of differentiation $\left(\chi^{2}=6.72, \mathrm{p}=0.035\right)$ and lymphatic metastasis $\left(\chi^{2}=4.874, p=0.027\right)$ of gastric cancer. Efficacy evaluation of apatinib in GC showed that the disease control rate (DCR) was $46.87 \%$ in seprase-positive group and $15.38 \%$ in seprase-negative group $(\mathrm{p}<0.05)$. As shown in table 1. The median progression-free survival (PFS) of two groups was 5.1 months and 3.0 months $(p<0.05)$.

Conclusions Seprase play important roles in the invasion and metastasis of gastric cancer, apatinib make clinical benefit to Seprase-positive gastric cancer patients and thus provide a new direction for target therapy.

Abstract IDDF2018-ABS-0053 Table 1 The correlation between Seprase expression and clinical efficacy on apatnib

\begin{tabular}{lcccccccc}
\hline $\begin{array}{l}\text { Seprase } \\
\text { expression }\end{array}$ & N & CR & PR & SD & PD & DCR & $\chi^{2}$ & $\begin{array}{c}\text { P- } \\
\text { value }\end{array}$ \\
\hline+ & 32 & 1 & 4 & 10 & 17 & $46.87 \%$ & 3.900 & 0.048 \\
- & 13 & 0 & 1 & 1 & 11 & $15.38 \%$ & & \\
\hline
\end{tabular}

$\mathrm{p}<0.05$ 